\title{
意図的および無意図的に想起された自伝的記憶の 特定性の比較
}

\author{
雨宮 有里 ${ }^{1,2}$ 高 史明 東京大学 関口 貴裕 東京学芸大学
}

\author{
Comparison of the specificity of musically cued autobiographical memories \\ Yuri Amemiya, Fumiaki Taka (University of Tokyo), \\ and Takahiro Sekiguchi (Tokyo Gakugei University)
}

\begin{abstract}
This paper compared the specificity of recollections of autobiographical memories where musical cues for events were varied. We used music which was popular in the past as cues which were related to a larger number of past individual events (frequent events cues) and music which was typically only sung at graduation ceremonies as cues which were related to a smaller number of events (rare events cues). In the instructed retrieval condition, participants were told to listen to the music and to recall past events, whereas in incidental retrieval condition, the instruction was only to listen to the music. Then participants were asked to describe what they recalled while hearing the music. When frequent events musical cues were played, the specificities of the recalled events were higher in the instructed retrieval condition than in the incidental retrieval condition. In contrast, when rare events musical cues were played, there were no differences in the specificities of the recalled events.
\end{abstract}

Key words: involuntary memories, music, autobiographical memories.

The Japanese Journal of Psychology

2011, Vol. 82, No. 3, pp. 270-276

過去に経験した個人的出来事の記憶を自伝的記憶 (autobiographical memory) という。その想起形態に は思い出そうと意図して想起する意図的想起（voluntary recollection）と，思い出そうという意図がないの に出来事がふと意識にのぼってくる無意図的想起 (involuntary recollection）の二つがある。両者は，想 起意図の有無だけでなく想起された出来事の性質や検 索過程が異なる可能性が指摘されている（神谷, 2003)。このため先行研究では自伝的記憶の性質やメ カニズムを統合的に把握するため, 意図的想起と無意 図的想起がどのような点で異なるかの比較を行ってき た。このうち近年の研究では, 雨想起形態での出来事 の検索過程の違いを反映するものとして, 想起された

Correspondence concerning this article should be sent to: Yuri Amemiya, Life Skill Education Institute in the Graduate of School of Hosei University, Fujimi, Chiyoda-ku, Tokyo 102-8160, Japan (e-mail: twomoons_t@yahoo.co.jp)

研究の遂行にあたりご協力いただきました東京大学大学院 杉本 崇氏と貴重なアドバイスを頂きました法政大学 越智 啓太 先生に感謝いたします。

2 現所属：法政大学大学院ライフスキル教育研究所 出来事の特定性（specificity）を比較したものが多い (Berntsen, 1996, 1998; Berntsen \& Hall, 2004; Schlagman \& Kvavilashvili, 2008)。特定性とは想起さ れた出来事がどのくらい個別の経験を参照しているか を表す概念である。例えば “高校生のとき初めてのデ ートで水族館に行った”という想起内容は，その日時 や場所が特定可能であり特定性の高い出来事を想起し ていると言える。一方“昔はよく水族館に行った”と いう想起内容は時間的に広い範囲に及んでおり個別の 経験を参照していないため特定性の低い, 概括的な出 来事の想起である。

では，意図的想起と無意図的想起ではどちらが特定 性の高い出来事を想起しやすいのであろうか。先行研 究では, 無意図的想起の方が意図的想起よりも特定性 の高い出来事が想起されやすいという結果が得られて いる（Berntsen, 1996, 1998; Berntsen \& Hall, 2004; Schlagman \& Kvavilashvili, 2008)。例えば Berntsen （1998）や Berntsen \& Hall（2004）では, 意図的想起 のデータを手がかり語法（単語を手がかりとして過去 の出来事の想起を求める方法) で, 無意図的想起のデ ータを日誌法（日常生活の中での無意図的想起を実験 
参加者が記録する方法）でそれぞれ収集し，想起され た出来事の特定性を比較している。その結果, 無意図 的想起の方が意図的想起に比べ特定性の高い出来事が より多く想起されるという結果が得られた。これと同 様の結果は, 無意図的想起のデー夕を注意集中課題 （視覚検出課題に注意を集中し，その間の無意図的想 起を実験参加者が報告する方法）で収集した Schlagman \& Kvavilashvili（2008）でも報告されてい る。この結果を Berntsen \& Hall (2004) は, 自伝的 記憶が抽象度の異なる自伝的情報の階層構造で貯蔵さ れるという Conway \& Pleydell-Pearce (2000) のモデ ルを用いて説明している。この説明では，無意図的想 起が生じるのは主に特定性の高い出来事に関連した手 がかりに出会った時であり, それにより個別の出来事 が特定性の高い情報の階層から直接検索される。一 方, 意図的想起の場合, 想起手がかりの呈示を受け て，それに関連した自伝的情報の階層から特定性の高 い情報の階層へと検索がすすむ。だが，この検索がす べて特定性の高い出来事の階層へと到達するわけでは ない。このため, 無意図的想起の方が意図的想起より も特定性が高い出来事が多く想起される。

しかしながら, 上記の先行研究には, いくつかの点 で方法論上の問題がある。第一に, 先行研究では無意 図的想起と意図的想起とで想起の手がかりが異なって いる。例えば，日誌法を用いて無意図的に想起された 出来事の特定性を調べた研究では（Berntsen, 1998; Berntsen \& Hall, 2004), 多くの場合 “引き出しにしま われたラブレター”のように具体的な事物が想起手が かりとなっている。こうした具体的な事物は，そのラ ブレターをもらった瞬間のことなど特定の出来事の記 憶と結びついていると考えられる。一方，これらの研 究では, 無意図的想起と意図的想起の比較のために, 意図的想起条件として, 実験参加者に単語（例えば, 手紙）を手がかりとして過去の出来事の想起を求めて いる。この場合，例えば “手紙”という単語は，その 象徵機能により, 手紙にまつわる様々な出来事や, よ り抽象的な自伝的情報（例えば，小学校のとき文通を していた）へのアクセスを可能にすると考えられる。 このことから，両想起形態における想起された出来事 の特定性の違いは, 想起形態による検索過程の違いを 反映したものではなく, 出来事の想起を引き起こす手 がかりの違い，より具体的には想起手がかりがどれだ け多くの出来事と結びついたものであるかの違いを反 映したものである可能性が考えられる（Berntsen, 1998)。

第二に，先行研究では，無意図的想起を調べる方法 が意図的想起を調べる方法に比べ，特定性の低い出来 事をより検出しにくいものであった可能性がある。先 行研究では実験参加者に, 日常生活や別の課題の遂行 中に出来事の無意図的想起が生じたかをモニタリング
してもらい，それに気づいたら報告してもらうという 手続きをとっている。しかしながら，無意図的想起は 瞬間的な現象であり，そのことに気がつかないことも 多い（神谷, 2003)。そのため, このような手続きで 報告されるものは想起したことが強く意識されるもの に偏ることとなる。そして, そうした強い想起意識 は, 抽象度の高い概括的な出来事よりも, 特定性の高 い具体的な出来事の想起で多く経験されると予想され る。一方, 意図的想起を調べる場合は, 想起された出 来事をすべて報告してもらうため, 想起された出来事 のうち特定性の高い出来事に報告が偏るということは 少ないであろう。以上のように, 無意図的想起の方が 意図的想起よりも特定性の高い出来事が想起されると いう先行研究の結果は, 想起形態による検索過程の違 いを反映したものではなく, 想起手がかりや想起内容 の報告されやすさの違いが交絡したことで得られたも のである可能性がある。したがって, 意図的, 無意図 的に想起された出来事の特定性を比較するためには,

これらの方法論的問題を改善した検討を行う必要があ るだろう。

そこで本研究では, 意図的想起条件と無意図的想起 条件とで同じ想起手がかり，同じ報告基準を用いた実 験を行い, 条件間で想起される出来事の特定性の比較 を行う。そのために本研究では, 無意図的想起の手続 きとして雨宮・関口 $(2004,2006)$ の手続きを用い る。この手続きでは，まず実験参加者に自伝的記憶の 無意図的想起を誘発する課題を行わせる（例えば，想 起手がかりとなる単語の親密度評定)。次に, 誘発課 題のすぐ後に, 課題を行っている最中に過去の出来事 が無意図的に想起されたかを回想させ，想起したもの をすべて報告させる。この手法では, 誘発課題の刺激 として意図的想起条件の想起手がかりと同じものを呈 示することで，それぞれの想起形態でどのような出来 事が想起されるかを手がかりの違いを交絡させること なく調べることができる。さらにこの手法は, 誘発課 題の直後に, 実験者の指示によって無意図的想起の有 無を評価させるため, 従来の手続きでは報告されにく かった特定性の低い出来事の想起も検出可能であると 考えられる。

また，本研究では，想起手がかりに結びついた出来 事の多鿒も要因とし, 想起意図の有無の効果が, 少数 の特定の出来事（例えば，卒業式）と結びついた手が かりを用いた場合と多くの出来事に結びついた手かが りを用いた場合とでどのように異なるのかも検討し た。意罒的想起を対象とした先行研究では, 主に単語 を想起手がかりに用いてきた。しかし，すでに述べた ように言語には象徵機能があるため, 例えば “卒業 式”という特定の出来事とのみ結びついているように 思える単語も, テレビで見た卒業式の場面など様々な 出来事の記憶と結びついている。そのため少数の出来 
事とのみ結びついた単語を選定するのは難しい。これ に対して音楽や匂いなどの感覚刺激は象徵機能を持っ て扔らず，それに関わる特定の出来事とのみと結びつ いている。そのため, それを聴いたり，嗅いだりした 経験頻度によって, 少数の出来事とのみ結びついてい るものもあれば, より多くの出来事と結びついたもの もある。そこで, 本研究では感覚刺激のうち, 呈示が 容易で多くの実験参加者を対象にデー夕を収集するこ とに適した音楽を想起手がかりとして用いた。符号化 特定性原理（Thomson \& Tulving, 1970）から, 少数 の出来事と結びついた想起手がかりとは, その出来事 に固有の文脈として符号化された情報であると考えら れる。そこで少数の出来事と結びついた想起手がかり として, 卒業式でのみ頻繁に歌われる曲を用いた。一 方, 多くの出来事と結びついた想起手がかりには, そ れを聴いた経験の多いC Mソングなどの流行歌を使用 した。

\section{方 法}

\section{実験参加者}

大学生 408 名（平均年齢 19.4 歳, 男性 223 名, 女 性 184 名, 記述なし 1 名) が心理学関係の授業の一環 として, 匿名かつ自由意志で実験に参加した。実験参 加者は二つの講義の受講者であり, 講義 1 の受講者が 多くの出来事と結びついた想起手がかりの条件（出来 事多条件) に, 講義 2 の受講者が少数の出来事と結び ついた想起手がかりの条件（出来事少条件）にそれぞ れ参加した。さらにこれらの実験参加者は意図的想 起，無意図的想起の各条件のいずれかにランダムに割 り当てられた。条件ごとの実験参加者数は出来事多条 件に扔いて意図的想起条件 50 名, 無意図的想起条件 80 名, 出来事少条件において意図的想起条件 101 名, 無意図的想起条件 177 名であった。無意図的想起条件 の方が意図的想起条件よりも実験参加者数が多いの は, 前者の方が後者に比べ想起率が低いと予想し, 分 析可能なデー夕数を条件間でほぼ同数にするためであ つた。

\section{要因計画}

想起手がかり（出来事多・出来事少）と想起意図の 有無（意図的想起・無意図的想起）をともに実験参加 者間要因とする 2 要因計画であった。

\section{刺激素材}

出来事少条件 本実験の 2力月前に，同じ授業の受 講生 204 名に対して卒業式でどのような歌を歌ったか を調べる予備調査を行った。この調査の参加者は本実 験の参加者と重なっていたが, これは本実験において 卒業式の出来事に結びついた音楽を呈示するという操
作を確実にするためであった（卒業式の歌は人や地域 により大きく異なることが予想される)。調查は人種 偏見と価值観に関する調査の一部として行われ，質問 紙の形で実験参加者に呈示した。質問紙には卒業式で 歌うことが多いと考えられる 6 曲の曲名が印刷されて おり, 実験参加者にはその中から卒業式で歌ったこと があるものすべてを選択することと，その歌を歌った 時期の報告を求めた。その結果, 選択数が多かった “旅立ちの日に”と“仰げば尊し”を出来事少条件の 刺激素材とした。また, その経験時期は中学生時とい う報告が最も多かった。なお，この予備調查は他の調 査の中に組み込まれたものであり, 卒業式の歌のみに 意識を向けさせたり，それに関する想起を促したりす るものではなかった。また, 調查から本実験の実施ま でに 2力月の遅延期間を設けていた。以上のことか ら, 実験参加者が事前に予備調查に参加したことが, 本実験での出来事の想起に影響を与えた可能性は低い と考えられる。

出来事多条件 出来事多条件の刺激の選定のために 本実験の参加者が中学生であった 2003-2005 年の才 リコンチャート上位 5 曲のうち, タイアップがついて おり頻繁に耳にしたと考えられる11曲を刺激素材の 候補とした。その上で本実験とは別の同年代の回答者 15 名に対し, 5 名以下の小集団形式で音楽の聴取頻度 （7 段階）と関連情報数の調査を行った。関連情報数 は音楽に関連した出来事を文章で記述させ，その数を 指標とした。調查では各曲について曲のサビの部分 (約 15 秒)を呈示し，その終了直後に評価を行うよう 求めた。各曲の聴取頻度と関連情報数の平均値を求め たところ，“世界にひとつだけの花 (SMAP)”が両指 数ともに最も高く, “さくら (森山直太郎)” と“花 (ORANGE RANGE)”がそれに続いた。しかし“さ くら”は高校の卒業式で歌ったという報告が多く，多 くの実験参加者にとり特定の出来事と強く結びついた 想起手がかりである可能性が考えられた。そこで“世 界にひとつだけの花”と“花”を刺激素材として選定 した。

\section{想起された出来事の特定性の評価}

想起された出来事の特定性は, 後述の質問紙により 実験参加者自身に評価してもらった。質問文につい て, Berntsen \& Hall（2004）の質問文を直訳した“想 起された出来事が特定的出来事か/特定的出来事でな いか”という文を用いた予備実験を行ったところ，特 定的出来事という表現が理解できない，もしくは，あ まり経験しない特別な（special）出来事という判断基 準を用いたとの内観報告が多く得られた。そのため,

本研究では, Berntsen \& Hall（2004）の特定性の定義 をよりわかりやすい質問に直した“想起された出来事 はある日・あるときに経験した個別的な出来事か／何 
度も経験した出来事がぼんやりまとまったものか”と いう質問文により，特定性の評価を求めた。また，そ れに加えて, 実験参加者が報告した想起内容に対し 2 名の評定者が独立に特定性の評定を行い，それを外的 基準に基づく評定とした。

\section{質問紙}

無意図的想起 無意図的想起の誘発課題，および想 起内容を回答するための質問紙を冊子形式で作成し た。冊子には，まず無意図的想起誘発課題の教示とし て“音楽が, その後の課題にどのような影響を与える のかを調べるものです。音楽が流れたらそれをよく聴 いてください”と印刷されていた。次のページには, 無意図的想起の生起から報告までに遅延期間を設ける ためのフィラー課題（一桁の数字の計算課題）が印刷 されていた。このフィラー課題は, 予備調査におい て, 無意図的想起誘発課題と想起の報告が時間的に近 すぎると, どちらの段階で想起が起きたかの判別が困 難という指摘が得られたため用意した。その次のペー ジには，自伝的記憶の想起に関する質問文 “先ほど音 楽を聴いていただきましたが，その際に過去に経験し た出来事を思い出しましたか?”と想起の有無の報告 を求める回答欄が印刷されていた。そしてその下に想 起内容の記述を求める教示 “どのような出来事を思い 出しましたか？ 文章で記述を扮願いします。複数思 い出した場合は, 思い出した順番に出来事をお書きく ださい”とそのための回答欄が印刷されていた。ま た，プライバシー保護のため，具体的に記述したくな い場合にその旨を報告するチェック欄が用意されてい た。最後に, 操作チェックのために, 用意した想起意 図の有無を問う質問項目“何か思い出そうという気持 ちがあった/思い出そうという意図はなかった”と特 定性の判断を求める質問項目 “想起された出来事はあ る日・あるときに経験した個別的な出来事か／何度も 経験した出来事がぼんやりまとまったものか”が印刷 されていた。

意図的想起 冊子は無意図的想起条件のものとほぼ 同じであり, 想起課題の教示 “音楽に関連する課題を 行うことが，その後の課題にどのような影響を与える かを調べるものです。音楽が流れたら，それに関連す る過去の出来事を思い出してください” と, 出来事の 報告を求める質問文“先ほど音楽を聴いてそれに関連 する出来事を思い出す課題をしていただきましたが, その際に過去に経験した出来事を思い出しました か??”のみが異なっていた。

\section{手続き}

実験は授業時間内に集団形式で行った。実験の目的 は，音楽が認知に与える影響を調べることであると説 明した。まず実験参加者に，質問紙に印刷された無意
図的もしくは意図的想起課題の教示文を読ませた。次 に刺激素材である音楽（約 30 秒，2曲を連結したも の）を教室備品のスピーカーを用いて呈示した。そし て, 実験参加者にフィラー課題を 20 秒間行ってもら った後, 出来事の想起の有無とその内容の回答を求め た。これ以降の質問には各自のペースで回答してもら った。実験に要した時間はおよそ 20 分であり, 実験 終了後, 口頭でデブリーフィングを行った。

\section{結果}

\section{操作チェック}

意図的想起条件のデータのうち, 出来事の想起がな かった実験参加者（出来事多条件 10 名, 出来事少条 件 10 名)，および出来事を無意図的に想起したと報告 した実験参加者（出来事多条件 9 名, 出来事少条件 7 名）のデー夕を“意図的想起なし”とみなし，意四的 想起の生起率を算出した。その結果, 意図的想起の生 起率は, 出来事多条件で $62.0 \%$, 出来事少条件で 83.2 \%となった。同様に, 無意図的想起条件において出来 事の想起がなかった実験参加者（出来事多条件 44 名, 出来事少条件 36 名), および出来事を意図的に想起し たと報告した実験参加者（出来事多条件 5 名, 出来事 少条件 17 名), 回答を途中で放棄した実験参加者（出 来事少条件 4 名）のデー夕を“無意図的想起なし”と みなし, 無意図的想起の生起率を求めた。その結果, 無意図的想起の生起率は出来事多条件で $38.8 \%$, 出 来事少条件で $67.8 \%$ となった。両条件の想起生起率 は十分に高く，分析可能なサンプルサイズであったた め, 想起意図の操作は適切であったといえる。

\section{特定性}

実験参加者により個別的な出来事と評価された回答 を特定的な出来事, 何度も経験した出来事がまとまっ たものと評価された出来事を概括的な出来事とし, 想 起された出来事の特定性について分析を行った。その 際, 特定性に関する回答のなかった 11 名（意図的想 起条件の出来事多条件 1 名, 出来事少条件 3 名, 無意 図的想起の出来事多条件 4 名, 出来事少条件 3 名）の デー夕は久損値として扱った。各条件で想起された特 定的・概括的な出来事の比率をそれぞれ Table 1 に示 す。まず，出来事多条件で想起意図の有無により特定 的・概括的な出来事の比率に差があるかを検定したと ころ有意差が見られたため $\left(\chi^{2}(1, N=65)=4.92, p\right.$ $<.05)$, 残差分析を行った。その結果, 無意図的想起 条件では特定的・概括的な出来事の比率に有意差はな かったが，意図的想起条件では，特定的な出来事の方 が概括的な出来事よりもその比率が有意に高かった $(p<.01)$ 。このことから, 出来事多条件では, 意図的 想起条件の方が無意図的想起条件よりも, より高い確 
Table 1

実験参加者による概括的な出来事・ 特定的な出来事の評価の比率

\begin{tabular}{lcclll}
\hline & \multicolumn{2}{c}{ 出来事多 } & & \multicolumn{2}{c}{ 出来事少 } \\
\cline { 2 - 3 } \cline { 5 - 6 } \cline { 5 - 6 } & 概括的 & 特定的 & & 概括的 & 特定的 \\
\hline 無意図的想起 & $41.1 \%$ & $58.9 \%$ & & $37.8 \%$ & $62.2 \%$ \\
意図的想起 & $16.1 \%$ & $83.9 \%$ & & $26.6 \%$ & $73.4 \%$ \\
\hline
\end{tabular}

率で特定的な出来事が想起されたといえる。次に出来 事少条件において, 意眓的想起条件と無意眓的想起条 件とで概括的・特定的な出来事の比率に差があるかを 検討したところ, 有意差は見られなかったが $\left(\chi^{2}(1\right.$, $N=190)=2.64, n s)$, 両想起条件とも特定的な出来事 の方が概括的な出来事よりも有意に高い確率で想起さ れていた $(p<.01)$ 。

また本研究では，想起された出来事の記述をもと に, Baddeley \& Wilson（1986）の基準に従い 2 名の 評定者が 0 -3 の 4 段階（值が高いほど特定性が高い） で特定性の評定を行った（評定者間の一致率 79\%)。 しかしながら評定者の評定と実験参加者の評価の一致 度を点双列相関係数により評価したところ, 出来事少 条件で $r=0.08(n s)$, 出来事多条件でも $r=0.47(p<$ .05）とどちらも相関係数は低く, 出来事の特定性に 関する評定者の評定と実験参加者の評価が必ずしも一 致していないことが示された。実験参加者による評価 数の内訳は, 評定者が特定性 0 と評定したものに対し 概括 6 , 特定 4, 特定性 1 に対し概括 8 , 特定 11 , 特 定性 2 に対し概括 25 , 特定 44, 特定性 3 に対し概括 36, 特定 106 であった（内容の記述がなく特定性の評 定ができなかった 15 名のデー夕を除く)。本研究では 想起内容をどの程度詳細に書くかを実験参加者に具体 的に指定していなかった。そのため, 想起内容の記述 の詳細さの基準が実験参加者によって異なっていた可 能性がある。すなわち, 詳細な出来事を思い出したと しても，実験参加者によってはそれをそのまま詳しく 記述したかもしれないし，簡単に書く場合もあったか もしれない。そして，こうした実験参加者による記述 の詳細さの基準の違いが，記述内容を通じた特定性の 評定と実験参加者自身による評価が一致しなかった原 因となったのかもしれない。そこで本研究では, 評定 者の評定はあくまで実験参加者の記述をもとにした間 接的なものであることを踏まえ，実験参加者自身によ る評価の方が特定性の測度として妥当であるとみなし た。なお確認として, 評定者による評定值も分析した ところ, 出来事多条件における意図的想起条件の特定 性（中央值 $=2 ）$ は無意図的想起条件の特定性のそれ （中央值 $=1 ）$ より有意に高く $(U=301.0, p<.05)$, 一 方, 出来事少条件の特定性は想起意眓の有無による差 は見られなかった（ともに中央值 $=3, U=5026, n s$ )。
すなわち，評定者による評定においても，実験参加者 による特定性の評価と同じ結果が得られた。

\section{考察}

本研究は意図的に想起された出来事と無意図的に想 起された出来事とで, その特定性がどのように異なる か, またその違いが, 想起手がかりが多くの出来事と 結びついている場合と少数の出来事に結びついている 場合とで，どのように異なるかを検討した。その結 果, 多くの出来事と結びついた想起手がかりが呈示さ れた場合，意図的想起の方が無意図的想起に比べ，特 定性の高い出来事がより多く想起された。一方で, 少 数の出来事と結びついた想起手がかりが呈示された場 合, 意図的想起と無意図的想起とで特定性の高い出来 事を想起する比率に差は生じなかった。本研究の結果 は, 無意図的想起の方が意図的想起よりも特定性の高 い出来事が想起されるという先行研究 (Berntsen, 1996, 1998; Berntsen \& Hall, 2004; Schlagman \& Kvavilashvili, 2008）の結果とは異なるものである。 しかしながら, 序論で述べたように, これらの先行研 究にはいくつかの点で方法論的な問題がある。例えば, Berntsen (1996, 1998) や Berntsen \& Hall (2004)の 研究では, 無意図的想起と意眓的想起とで想起手がか りとなる刺激が統一されていない。一方, Schlagman \& Kvavilashvili（2008）の研究は, 両想起形態で同じ 想起手がかりを使用しているが，無意図的想起を調べ る方法が意図的想起を調べる方法に比べ，特定性の低 い出来事を検出しにくいものであったかもしれない。 これらのことから, 先行研究の結果は, 想起手がかり の違いや想起内容の報告されやすさの違いを反映した ものであった可能性が考えられる。これに対して本研 究は, 意図的想起条件と無意眓的想起条件とで同じ想 起手がかりを用いている。また, 無意眓的想起条件で は，想起の直後に教示によってそれに意識を向けさせ るため, 特定性の低い出来事であってもそれを検出可 能である。したがって本研究の結果は, 両条件での想 起手がかりの違いや想起内容の検出しやすさの違いを 反映したものではなく，それぞれの想起形態で，自伝 的記憶の検索がどのように進行したかの違いを反映し たものだと考えられる。

では, 本研究の結果を, 自伝的記憶の検索過程から どのように説明が可能だろうか。本研究では, Conway \& Pleydell-Pearce (2000) の階層構造モデル をもとに以下のように考えた。まず，多くの出来事と 結びついた想起手がかりが入力された場合, 意図的想 起, 無意戝的想起ともに, 様々な出来事が抽象化され た情報を貯蔵する特定性の低い階層において, それに 関連した自伝的情報が活性化すると考えられる。この ように両想起形態は, はじめにアクセスする階層は同 じであるが, その後の検索過程が異なる。意図的想起 
の場合，参加者には過去に経験した出来事を想起する という目的が与えられている。そして，この目的は出 来事の詳細情報を想起することによって達成されるた め (Conway \& Pleydell-Pearce, 2000), 特定性の高い 情報が保持された階層へと能動的な検索が行われる。 これは Conway \& Pleydell-Pearce（2000）の生成的検 索（generative retrieval）に当たると考えられる。一 方，無意眓的想起の場合，過去の出来事を想起すると いう目的はない。そのため, 検索は特定性の高い階層 へ進むように方向づけられておらず，多くの場合，は じめに活性化した自伝的情報がそのまま意識にのぼる (直接的検索：direct retrieval)。この結果，意図的想 起の方が無意図的想起よりも特定性の高い出来事を想 起しやすくなるのではないだろうか。

一方, 少数の特定の出来事と結びついた想起手がか りが入力された場合, 意図的想起, 無意図的想起とも に, 出来事の詳細情報を貯蔵する特定性の高い階層で それに関連した自伝的情報が活性化する。この時, 意 図的想起では, 特定性の高い出来事を想起しょうとす るが，すでにそれに関連する情報が活性化しているた め, さらに検索を進める動機は生じない。また, 無意 戝的想起の場合, 検索の方向づけがないため, やはり 特定性の高い出来事の情報がそのまま想起される。こ のために両想起形態ともに特定性の高い出来事を同程 度の確率で想起したと考えられる。

Berntsen \& Hall（2004）は，無意図的想起は常に特 定性の高い階層からの直接的検索により生じると考え ていたが，そう考えた場合，出来事多条件の無意図的 想起条件において, 特定性の高い出来事と特定性の低 い概括的な出来事が同程度の確率で想起されたことを 説明できない。これを説明するためには，むしろ上記 のように, 無意図的想起も意戝的想起と同様, 様々な 特定性の情報にアクセス可能であると考える必要があ る。そして, 両想起形態での想起される出来事の違い は, 検索の開始位置の違いではなく, その後の能動的 な検索の有無を反映するのではないだろうか。また, 意図的想起，無意図的想起ともに，どの階層に最初に アクセスするかは，想起のための手がかりがどの程度 多くの出来事と関連したものであるかにより異なって おり, 少数の特定の出来事と結びついた手がかりから は, 特定性の高い情報の階層へとアクセスが行われ， 一方, 多くの出来事と結びついた手がかりからは, 抽 象的な情報の階層へと最初のアクセスが行われるので あろう。

なお, 本研究の問題点として, 出来事少条件で, 想 起手がかり（卒業式の歌）を選出するための予備調査 の参加者と本実験の参加者が同じであったことがあげ られる。この予備調査は, 他の調査の一部として行わ れ，また調查から本実験までに2カ月の間をとったた め, それへの参加が本実験での出来事の想起に影響を
与えることはないと考えた。しかしながら，実験の結 果, 出来事少条件では, 意図的想起条件, 無意図的想 起条件ともに特定性の高い出来事 (卒業式の出来事) が比較的高い確率で想起されており, これに予備調查 において卒業式の歌を考えたことの影響がないとは断 言できない。今後, 出来事少条件でも, 本実験とは別 の実験参加者を対象に予備調查を行い, この可能性を 排除した上で本研究と同じ結果が得られるかを検討す る必要がある。

また, 本研究では, 実験参加者と評定者とで想起さ れた出来事の特定性の評価が一致しなかった。そこで 評定者の評定が間接的なものであることを踏まえ，実 験参加者自身による評価を特定性の測度として採用し た。しかしながら，この二つの測度にはそれぞれに異 なる利点と欠点がある。まず, 実験参加者自身による 評価は, 想起内容に対しての直接的な評価であるとい う利点の一方で，どのような出来事を特定性の高い出 来事と判断するかの基準が個人によって異なる可能性 があるという欠点がある。これに対し, 評定者による 評定は，外的指標をもとに一定の基準で特定性を評定 できるという利点があるが，一方で，実験参加者の記 述内容をもとにしたものであるため, その評定が想起 内容の記述の程度に影響されるという問題がある。こ のように二つの測度には，それぞれ一長一短があり， 今後, 特定性の指標としてどちらの測度を用いること が妥当であるかについては, 慎重に議論する必要があ るだろう。同時に, この二つの測度の一致率を上げる ような工夫，例えば，想起内容の記述の程度を実験参 加者に具体的に指示することなども必要であろう。

最後に, 本研究では無意図的想起の想起手がかりと しての音楽の有効性が示された。これまで無意図的想 起の実験的検討では, 想起手がかりとして単語を用い ることが多かった（雨宮・関口，2006; Schlagman \& Kvavilashvili, 2008)。しかし, 言語は象徽機能を持つ ため, 自ら経験した出来事以外の出来事も含め様々な 出来事と関連している。これに対し, 音楽はある時期 に流行し, 様々な出来事と結びついたものから, 少数 の出来事とのみ結びついたものまで出来事の結びつき を要因として操作しやすい。また, 多くの実験参加者 に対して容易に呈示可能という利点もある。今後, 音 楽を想起手がかりとしたさらなる実験的検討を行うこ とで, 無意図的想起を引き起こしやすい想起手がかり やその性質について，より多くのことを明らかにでき るだろう。

\section{引用文献}

雨宮 有里・関口 貴裕 (2004). 自伝的記憶の無意図 的な想起に関する実験的検討 東京学芸大学紀要 第 1 部門 教育科学, $\mathbf{5 5}, 93-99$. 
(Amemiya, Y., \& Sekiguchi, T. (2004). An experimentally study on involuntary recollection of autobiographical memories. Bulletin of Tokyo Gakugei University, 55, 93-99.)

雨宮 有里・関口 貴裕 (2006)。無意図的に想起され た自伝的記憶の感情価に関する実験的検討 心理 学研究, 77, 351-359.

(Amemiya, Y., \& Sekiguchi, T. (2006). An experimental study of the emotional valence of involuntarily recalled autobiographical memories. Japanese Journal of Psychology, 77, 351-359.)

Baddeley, A. D., \& Wilson, B. A. (1986). Amnesia, autobiographical memory and confabulation. In D. C. Rubin (Ed.), Autobiographical memory. Cambridge: Cambridge University Press. pp. 225252.

Ball, C. T., Mace, J. H., \& Corona, H. (2007). Cues to the gusts of memory. In J. H. Mace (Ed.), Involuntary memory. Malden, MA: Blackwell. pp. 113-126.

Berntsen, D. (1996). Involuntary autobiographical memories. Applied Cognitive Psychology, 10, 435454.

Berntsen, D. (1998). Voluntary and involuntary access to autobiographical memory. Memory, 6, 113-141.
Berntsen, D., \& Hall, N. M. (2004). The episodic nature of involuntary autobiographical memories. Memory \& Cognition, 32, 789-803.

Conway, M. A., \& Pleydell-Pearce, C. W. (2000). The construction of autobiographical memories in the self-memory system. Psychological Review, 107, 261-288.

神谷 俊次 (2003)。不随意記憶の機能に関する考察 ——想起状況の分析を通じて—— 心理学研究, 74, 444-451.

(Kamiya, S. (2003). Some observations on the functions of involuntary memory: An analysis of the circumstances surrounding occurrence. Japanese Journal of Psychology, 74, 444-451.)

Schlagman, S., \& Kvavilashvili, L. (2008). Involuntary autobiographical memories in and outside the laboratory: How different are they from voluntary autobiographical memories? Memory \& Cognition, 36, 920-932.

Thomson, D. M., \& Tulving, E. (1970). Associative encoding and retrieval: Weak and strong cues. Journal of Experimental Psychology, 86, 255-262.

— 2009.1.16 受稿, 2011.1.22 受理—— 